\title{
Light Intensity and Lettuce Growth in an Apartment Balcony Affected by the Direction of Balcony
}

\author{
Yoonah Jang*, Sun Jin Jeong, Kyeong Suk Han, Sang Mi Lee, Jung Nam Suh, and Kwang Jin Kim \\ National Institute of Horticultural and Herbal Science, RDA, Wanju-gun, Jeollabuk-do 55365, South Korea
}

\begin{abstract}
Light is very important for plant growth and a major limiting factor in indoor plant cultivation, such as in balconies. This study was conducted to investigate the light intensity and lettuce (Latuca sativa L.) growth in an apartment balcony affected by the direction of balcony. Photosynthetic photon flux (PPF), air temperature, and relative humidity in the east-, south-, or west-facing balcony were measured for a year. The lettuce was grown in the east-, south-, or west-facing balcony. The time and amount of light entering into the balcony differed according to the direction of the balcony window. Whereas light entered into the east-facing balcony from sunrise to noon, it entered into the west-facing balcony afternoon before sunset. The temperature and humidity in the balcony also varied according to the direction of the balcony window. Daily Light Integral (DLI) in the south-facing balcony was 20 50\% of outdoor and DLI in east- or west-facing balconies was 10 20\%. Also, the environmental characteristics of the balconies were affected seasonally. In the spring (from March to May), the DLI was around $10 \mathrm{~mol} \cdot \mathrm{m}^{-2} \cdot \mathrm{day}^{-1}$ and the average temperature was around $25^{\circ} \mathrm{C}$. But the DLI was below $10 \mathrm{~mol} \cdot \mathrm{m}^{-2} \cdot$ day $^{-1}$ and the average temperature and relative humidity were around $30^{\circ} \mathrm{C}$ and over $60 \%$, respectively, in the summer (from June to August). In the balcony, the average temperature was maintained around $10^{\circ} \mathrm{C}$ even in winter, which is a condition of freezing outdoor. Growth of the lettuce in the south-facing balcony was better than that of the other directions. This is attributed to better environmental conditions of south-facing balcony. Therefore, considering the environmental characteristics of the balcony, selection and management of crops with relatively low light demand like leafy vegetables are required. It is also recommended to cultivate crops from autumn to spring.
\end{abstract}

Keywords: daily light integral (DLI), light, photosynthetic photon flux (PPF), relative humidity, temperature

\section{Introduction}

With emerging multi-functionality, diverse effects and advantages of urban agriculture, the area and number of participants of urban vegetable gardens has been dramatically increasing (MAFRA, 2016). However, it is difficult to secure appropriate spaces for urban agriculture in downtown, which is becoming an obstacle to expanding and vitalizing urban agriculture (The Seoul Institute, 2012). Therefore, it is necessary to use various spaces including apartment complexes, schools, hospitals, religious facilities, parks, unoccupied city lands, rooftops of buildings, verandas and balconies for urban agriculture.

This research was supported by the National Institute of Horticultural and Herbal Science, the Rural Development Administration, Republic of Korea (Project No. PJ01137401).

Received: September 18, 2017, Revised: October 14, 2017, Accepted: October 19, 2017

*Comesponding author: limejya@korea.kr 
Apartment is a typical residential space in South Korea. The number of households living in apartments accounted for 47.1\% in 2010 and has been increasing (Statistics Korea, 2017). Balconies in apartments, commonly called verandas, are the buffer spaces that connect the exterior and interior of the building after being additionally installed on the exterior wall of the building for view and relaxation (Kim et al., 2006). Balconies in South Korea are generally used as independent spaces, which are separated from the outdoors and indoors, as windows are installed on the interior face of the exterior wall. Indoor gardening using the balcony spaces has advantages that can be done indoors without burdens to go outside and can be frequently managed and participated in (RDA, 2016). As it has another advantage of growing plants even in early spring or late autumn, in which it is difficult to do outside, there has recently been increasing interests and participation in gardening in the balcony spaces of apartments (Kim et al., 2015).

However, since balconies lack PPF for plant growth although the spaces have the highest indoor PPF, PPF becomes the biggest obstacle to making indoor vegetable gardens. It was found that the highest PPF in south-facing balconies was only a half of the highest PPF in greenhouses in mid October (Moon et al., 2007). In addition, the characteristics of temperature and humidity of balconies were different from the outdoors (Oh and Choi, 2006). Leaf vegetables were recommended growing in balconies based on a comparison among the growth of nine species of leaf vegetables under different light conditions (Moon et al., 2007). The species of ornamental plants were recommended by the light condition after identifying the light intensity and temperature and humidity of balconies in apartments by floor and season and reviewing the growth of ornamental plants depending on the light intensity (Son, 2009).

Photosynthetic photon flux (PPF, unit: $\mu \mathrm{mol} \cdot \mathrm{m}^{-2} \cdot \mathrm{s}^{-1}$ ) or light intensity (illuminance, unit: lux) is an instantly measured value at a certain point based on the amount of photon or the intensity of light measured in a certain area at a unit time (Torres and Lopez, 2010). Since the natural PPF keeps changing, the PPF at a certain point in a day cannot represent the PPF that plants receive in a day. Daily light integral (DLI, unit: $\mathrm{mol} \cdot \mathrm{m}^{-2} \cdot \mathrm{d}^{-1}$ ) is the total PPF values that plants receive in a day, which changes depending on latitude, season, sunshine hours, and weather.

There are different directions of balcony windows in apartments including the west-facing, east-facing, north-facing, southeast-facing and south-west facing windows. Depending on the window directions, the incoming outdoor PPF or the time and period of incoming sunlight change as well as DLI. The solar altitude changes depending on the period (season). Therefore, the incoming indoor PPF or the distribution of the indoor PPF can change depending on the changes of the angle of incidence. Such environments in balconies can affect the growth of plants (RDA, 2016). However, there are lacking researches or specific information on the influences.

This study researched PPF, DLI and temperature and humidity depending on the window directions over an year in the balcony experimental facility with the east-facing, south-facing and west-facing balconies, to suggest the indoor environmental characteristics depending on the window directions of balconies and provide subsequent information of plant growth. It also reviewed the impacts of different indoor environmental conditions depending on the window directions of balconies on the growth of leaf lettuce.

\section{Research Method}

\section{Balcony Experimental Facility}

This study was conducted in the balcony experimental facility of National Institute of Horticultural and Herbal Sciences in Jeonju. The facility is a u-shaped one-storied reinforced concrete building with balconies on three sides in the east, south and west. Each balcony was connected to the living room with corridor access (Fig. 1). The size of each balcony was 4.5 (length) $\times 1.5$ (width) $\times 2.5 \mathrm{~m}$ (height) with the $6.75 \mathrm{~m}^{2}$ sized floor. On the exterior faces of each balcony, balcony 


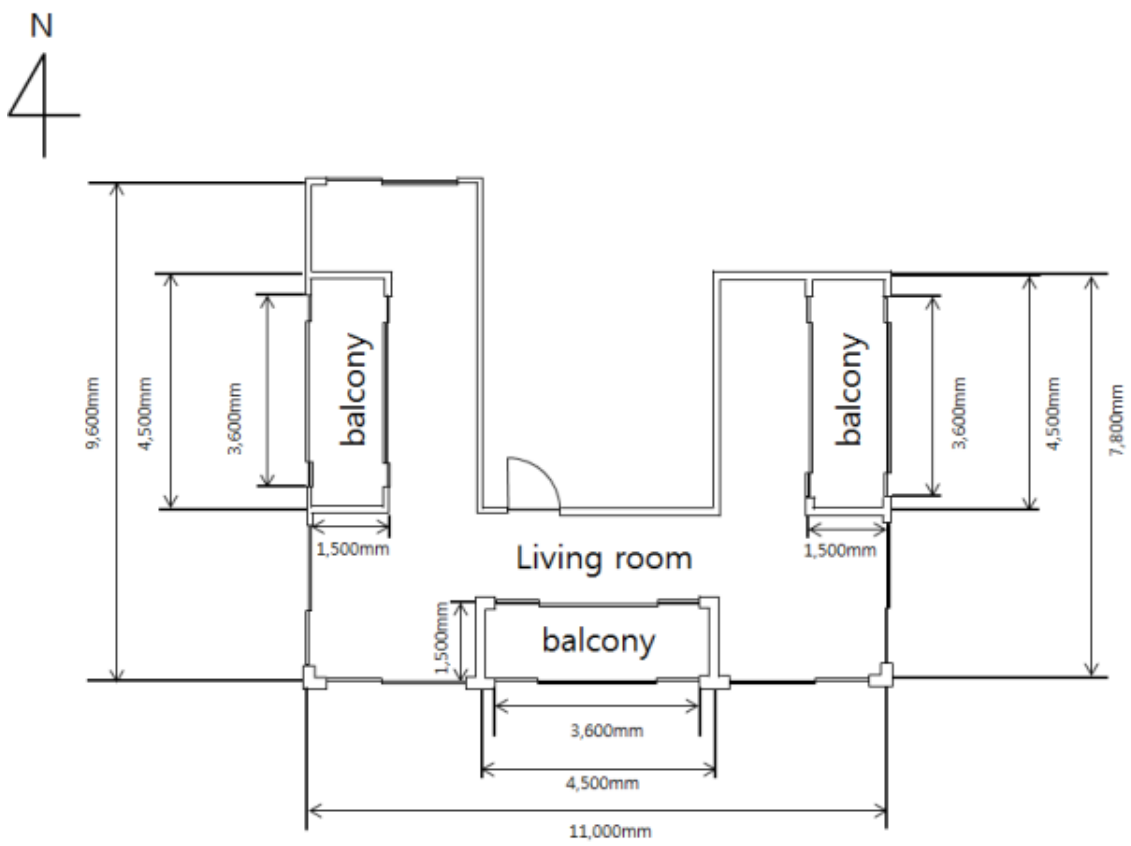

Figure 1. The experimental facility used for monitoring the environment and growing plants in the balcony.

windows sized $3.6 \mathrm{~m}$ (length) $\times 2.4 \mathrm{~m}$ (height) were installed. The balcony windows were composed of the fixed windows at the center and the sliding windows on both sides. The sliding windows opened and closed for ventilation depending on the weather. In the livingroom inside the balconies, two heating and air conditioning systems (PNW0520R2SJ, LG Electronics, South Korea) were installed and operated to maintain the temperature of the living room at around $25^{\circ} \mathrm{C}$ throughout the year.

\section{Environmental Data Collection Inside and Outside of the Balconies}

To measure the changes of PPF and temperature and humidity in the balconies throughout the year, the PAR (Photosynthetically Active Radiation) sensor (LightScout Quantum Light sensor, Range/Resolution $0 \sim 2,500 \mu \mathrm{mol} \cdot \mathrm{m}^{-2} \cdot \mathrm{s}^{-1}$, Accuracy $\pm 5 \%$, Spectrum Technologies, Inc., USA) and the data logger embedded with the temperature-humidity sensor (WatchDog 1,000 Series Micro Stations, Temperature range $-40 \sim 85^{\circ} \mathrm{C}$, Accuracy: $\pm 0.6^{\circ} \mathrm{C}$ at -20 to $50^{\circ} \mathrm{C}$, else $\pm 1.2^{\circ} \mathrm{C}$, RH range $0 \sim 100 \%$, Accuracy: $\pm 3 \%$ at $25^{\circ} \mathrm{C}$ and $10 \sim 90 \%$, else $\pm 5 \%$, Spectrum Technologies, Inc., USA) were installed at the center of the windows in the east-facing, south-facing and west-facing balconies $(0.1 \mathrm{~m}$ towards the inside from the windows and $1.2 \mathrm{~m}$ above the floor). The data was collected per 30 minutes from January to December in 2016. By adding the quantities of light per hour, DLI was calculated. During the data collection, some of the data (including the quantities of light outdoors in July and August) were omitted due to the error of the measurement sensor.

\section{Growing Lettuce in the Balconies}

The seedlings of the 'Jangsu' variety of red leaf lettuce (Latuca sativa L.) and the 'Hacheong' variety of green leaf lettuce that reached the best time of transplanting were transplanted in $12 \mathrm{~cm}$ sized pots ( $608 \mathrm{~mL}$ in volume) filled with the gardening bed soil (Baroker bed soil, Seoul Bio) on October 12, 2016. The pots where lettuces were planted were put in the east, south and west-facing balconies. The 'Jangsu' and 'Hacheong'varieties were grown for 83 and 111 days during, respectively. During the growth, the air was ventilated by opening the windows depending on the weather in order to 
prevent the indoor temperatura and relative humidity from rising. Watering was basically provided once a day and the watering interval was adjusted to the condition of the bed soil depending on the weather as the plants were not watered in rainy days. Overhead irrigation was applied to water the plants thoroughly until the water runs down into the drain under the pots. From the second week after transplanting, the leaf number and fresh weight of the harvested leaves were measured at its harvest time per two weeks.

\section{Data Analysis}

The collected environmental data (PPF, temperature, relative humidity) was analyzed using Sigma Plot v.13 (Systat Software Inc., UK) and the SAS (v.9.4 SAS Institute, USA).

\section{Results and Discussions}

Light is one of the critical environmental elements to plant growth as it engages in photosynthesis, phototropism and photomorphogenesis of plants (Burgess, 2009). The intensity and hours of sunlight vary by latitude and season. In the equator zone, they tend to be consistent throughout the year but change a lot depending on the season in the higher latitudes. Fig. 2 indicated the change in the outdoor PPF and the PPF in the balconies in a sunny day in February (winter), May (spring), August (summer) and early November (autumn) to find out the change in the values depending on the season. The incoming PPF values in the balconies were different depending on the direction of the balcony windows. The outdoor PPF and the incoming indoor PPF changed by month depending on the change in the solar altitude. In the east-facing balcony, light started to come indoors as the sun rose and peaked at the maximum PPF at around 10 am and almost no light came in after midday. In the west-facing balcony, it was the opposite. Almost no light came indoors in the morning but PPF started to increase after noon and peaked at the highest at around $2 \mathrm{pm}$. In the south-facing balcony, light

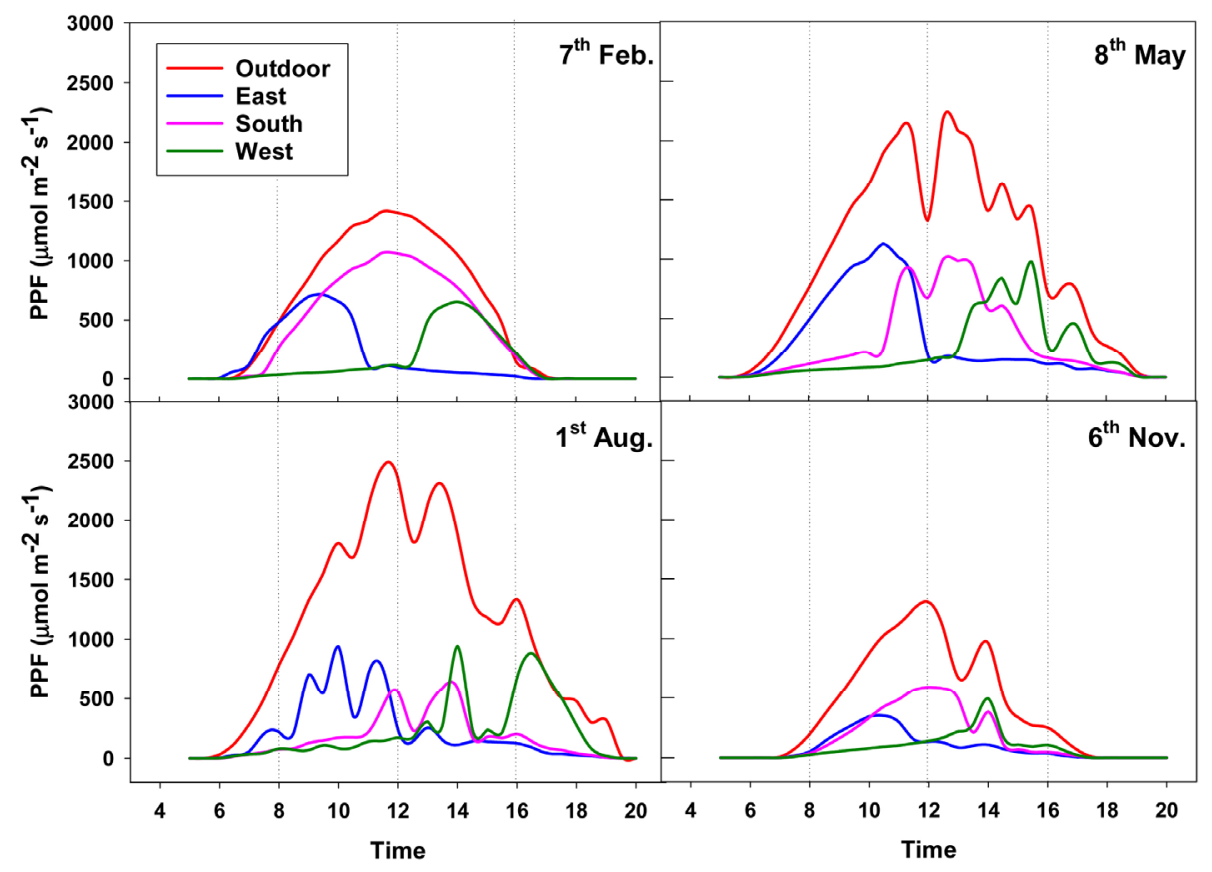

Figure 2. Photosynthetic photon flux (PPF) during the day outside and inside the balconies (facing east, south, and west side) on $7^{\text {th }}$ January, $8^{\text {th }}$ May, $1^{\text {st }}$ August, and $6^{\text {th }}$ November 2016. 
started to come indoors slightly later than the east-facing balcony. However, as PPF changed similarly according to the outdoor PPF and time, light came indoors during most of the daytime.

The highest outdoor PPF was $1,414 \mu \mathrm{mol} \cdot \mathrm{m}^{-2} \cdot \mathrm{s}^{-1}$ in February, $2,047 \mu \mathrm{mol} \cdot \mathrm{m}^{-2} \cdot \mathrm{s}^{-1}$ in May, $2,456 \mu \mathrm{mol} \cdot \mathrm{m}^{-2} \cdot \mathrm{s}^{-1}$ in August and $1,304 \mu \mathrm{mol} \cdot \mathrm{m}^{-2} \cdot \mathrm{s}^{-1}$ in November. In February, the highest PPF in the east, south and west-facing balconies was 51,75 and $46 \%$ of the outdoor PPF, respectively. On the other hand, the maximum PPF in the three balconies in August when the outdoor PPF was more than 70\% higher than in February, was 38, 24 and 38\% of the outdoor PPF, respectively. While the length of day is the longest and the amount of isolation is the highest in a year around the summer solstice (Burgess, 2009), the incoming indoor PPF ratio decreased as the solar altitude went up in June. In particular, in the south-facing balcony where light came indoors mostly during the daytime, the incoming PPF ratio tended to be lower than the east and south-facing balconies as the solar altitude increased.

The day length in the balconies tended to be shorter than the outdoors and the value in the south and west-facing balconies tended to be shorter than the east-facing balcony (Fig. 3). Whereas the day length in the east and south-facing balconies in May and June when the outdoor day length was more than 14 hours was one hour shorter than the outdoors, the indoor and outdoor day length in December was similar to each other when the day length was around 9 hours.

According to the change in the monthly average DLI, which is the total amount of incoming light in a day, the outdoor DLI increased to the highest around the summer solstice in June and slightly declined in December at $17 \mathrm{~mol} \cdot \mathrm{m}^{-2} \cdot \mathrm{day}^{-1}$ in January, $49 \mathrm{~mol} \cdot \mathrm{m}^{-2} \cdot$ day $^{-1}$ in May, $46 \mathrm{~mol} \cdot \mathrm{m}^{-2} \cdot$ day $^{-1}$ in August and $13 \mathrm{~mol} \cdot \mathrm{m}^{-2} \cdot$ day $^{-1}$ in December (Fig. 4). According to Faust (2002), the DLI in the facility was $26 \mathrm{~mol} \cdot \mathrm{m}^{-2} \cdot$ day $^{-1}$ on a sunny day and $12 \mathrm{~mol} \cdot \mathrm{m}^{-2} \cdot$ day $^{-1}$ on a cloudy day in June depending on the season and weather. On the other hand, the DLI on a sunny day in December was $9 \mathrm{~mol} \cdot \mathrm{m}^{-2} \cdot$ day $^{-1}$, lower by $25 \%$ than on a cloudy day in June, which is because the length of day is shorter in December than in June.

The DLI in balconies is a difference between the incoming indoor PPF and the amount of incoming light depending on the direction of the balcony windows. The value was generally high in the south-facing balcony. The monthly average DLI in the south-facing balcony was $8 \mathrm{~mol} \cdot \mathrm{m}^{-2} \cdot$ day $^{-1}$ in January, $10-19 \mathrm{~mol} \cdot \mathrm{m}^{-2} \cdot$ day $^{-1}$ from February to May, 6-7 $\mathrm{mol} \cdot \mathrm{m}^{-2} \cdot$ day $^{-1}$ from June to July, $10 \mathrm{~mol} \cdot \mathrm{m}^{-2} \cdot$ day $^{-1}$ in August and $7-8 \mathrm{~mol} \cdot \mathrm{m}^{-2} \cdot$ day $^{-1}$ from September to December. The value was over $50 \%$ of the outdoor DLI from December to March and 20\% from May to September. The DLI in the east and west-facing balconies was $10-20 \%$ of the outdoor DLI. In the east-facing balcony, the DLI was 12 and $11 \mathrm{~mol} \cdot \mathrm{m}^{-2} \cdot$ day $^{-1}$ in May and August, respectively, and less than $10 \mathrm{~mol} \cdot \mathrm{m}^{-2} \cdot \mathrm{day}^{-1}$ at in other periods.

DLI is closely related to plant growth (Faust, 2002). As DLI increases, the growth amount and branch number also

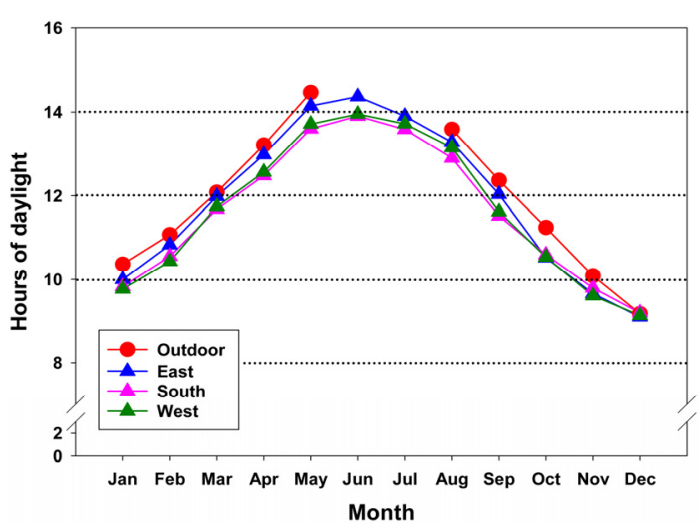

Figure 3. The monthly mean of day length outside and inside of the balconies (facing east, south, and west side) from January to December 2016.

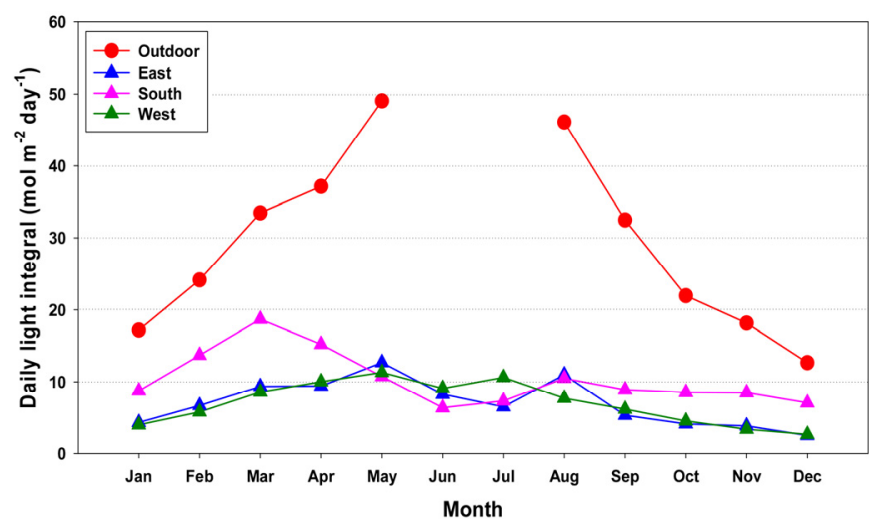

Figure 4. The monthly mean of daily light integral (DLI) outside and inside of the balconies (facing east, south, and west side) from January to December 2016. 
increases, the flowering time becomes shorter and the size and number of flower rises. Faust (2002) categorized DLI into five stages from the very low PPF to the very high PPF depending on the plant response. Under the very low light condition less than $5 \mathrm{~mol} \cdot \mathrm{m}^{-2} \cdot$ day $^{-1}$, plants are difficult to grow ordinarily or flower. The flowering time can be delayed or even if the plants flower, the number of size of the flower may be small or the plants can stay in the stage of vegetative growth without moving on to the next stage of reproductive growth. Under the low light condition of $5-10 \mathrm{~mol} \cdot \mathrm{m}^{-2} \cdot \mathrm{day}^{-1}$, plant growth is highly influenced by the temperature. Under the fresh condition at around $18^{\circ} \mathrm{C}$, plants grow slowly but in good quality. However, if the temperature goes up to more than $23^{\circ} \mathrm{C}$, the growth and development and quality of plants becomes bad. Under the appropriate condition of $10-20 \mathrm{~mol} \cdot \mathrm{m}^{-2} \cdot$ day $^{-1}$, most of the crops in the facility were grown in good quality and it was relatively easier to water them than the higher light condition. Under the high light condition of 20-30 $\mathrm{mol} \cdot \mathrm{m}^{-2} \cdot \mathrm{day}^{-1}$ or the very high light condition of $30-60 \mathrm{~mol} \cdot \mathrm{m}^{-2} \cdot \mathrm{day}^{-1}$, plants can be grown in better quality but the increased temperature due to the higher PPF can be an obstacle to plant growth. The DLI requirement for the optimal plant growth was identified to be $20-30 \mathrm{~mol} \cdot \mathrm{m}^{-2} \cdot$ day $^{-1}$ for chili and tomato and $14-16 \mathrm{~mol} \cdot \mathrm{m}^{-2} \cdot$ day $^{-1}$ for lettuce (Dorais, 2003 : Dzakovich et al., 2015; Morgan, 2013).

The temperature in the balconies changed by the incoming light depending on the direction of the balcony windows. In the morning, the temperature was high in the east-facing balcony and it was high in the afternoon in the west-facing balcony. The temperature was the highest at midday at around $1 \mathrm{pm}$ in the south-facing balcony (Fig. 5). The temperature changed depending on the direction of the balcony windows in February when the lowest outdoor temperature was $-9.4^{\circ} \mathrm{C}$ and the highest was $19.2^{\circ} \mathrm{C}$. However, the lowest temperature in the balconies was over $5^{\circ} \mathrm{C}$. During the high-temperature period, the difference between the indoor and outdoor temperature was not huge due to ventilation. The relative humidity tended to decrease depending on the temperature increase in the balconies (Fig. 6). The monthly average temperature in the balconies was $10-30^{\circ} \mathrm{C}$ depending on the period at the highest of $27-49^{\circ} \mathrm{C}$ and the lowest of $2-23^{\circ} \mathrm{C}$ (Fig. 7). The monthly average relative humidity in the balconies was $25-72 \%$ at the highest of $50-100 \%$ and the lowest of $7-44 \%$ (Fig. 8).

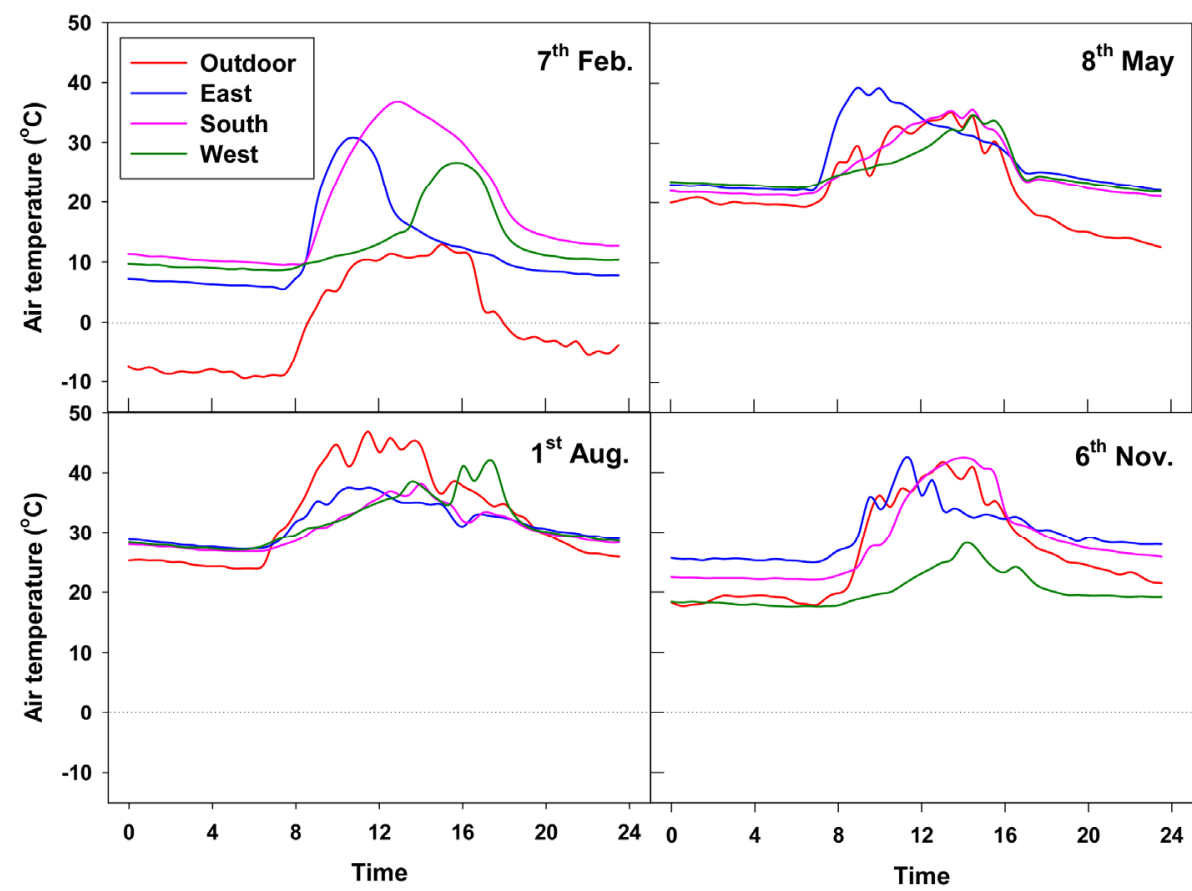

Figure 5. Air temperature outside and inside the balconies (facing east, south, and west side) on $7^{\text {th }}$ January, $8^{\text {th }}$ May, $1^{\text {st }}$ August, and $6^{\text {th }}$ November. 


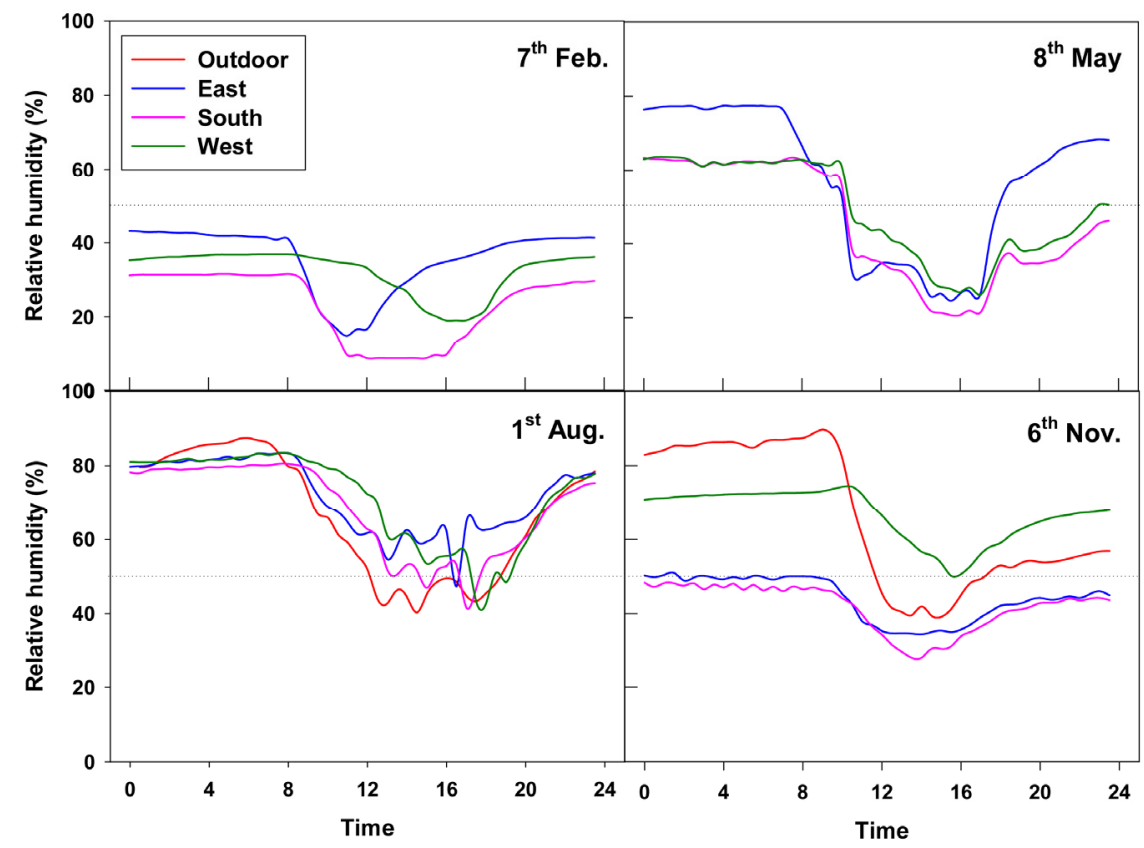

Figure 6. Relative humidity outside and inside the balconies (facing east, south, and west side) on $7^{\text {th }}$ January, $8^{\text {th }}$ May, $1^{\text {st }}$ August, and $6^{\text {th }}$ November.

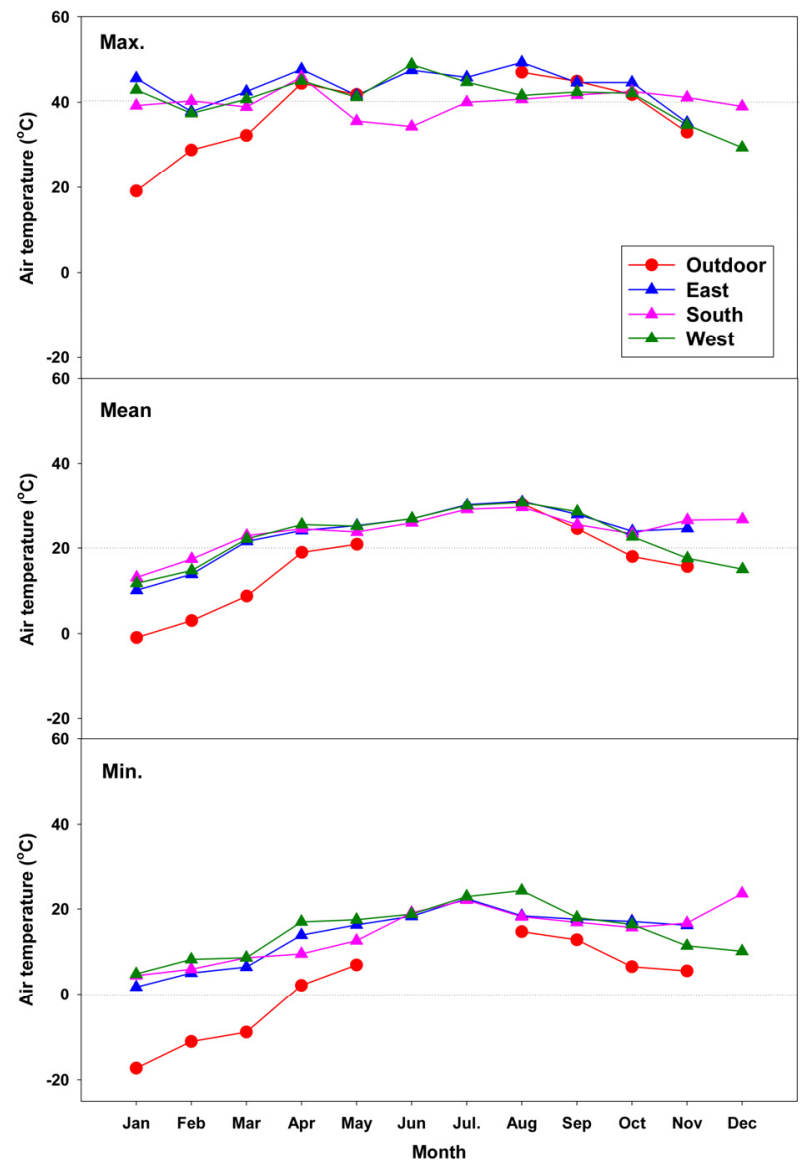

Figure 7. The monthly maximum (max.), mean, and minimum (min.) air temperature outside and inside of the balconies (facing east, south, and west side).

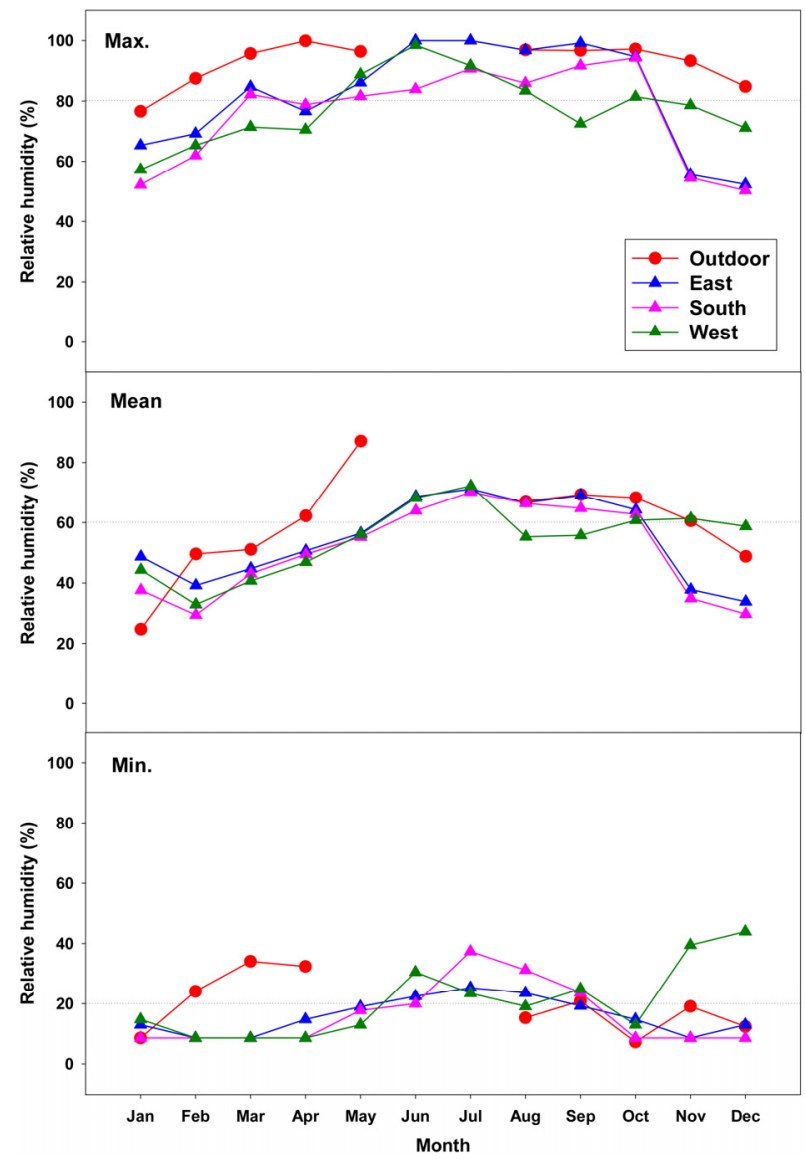

Figure 8. The monthly maximum (max.), mean, and minimum (min.) relative humidity outside and inside of the balconies (facing east, south, and west side). 
The yields of the lettuce grown in the balconies were different depending on the direction of the balcony windows (Fig. 9). The lettuce in the south-facing balcony had more leaves than the lettuce grown in the east and west-facing balconies. This is considered to be caused by the higher DLI and temperature in the south-facing balcony during October to January compared to the east and west-facing balconies. In the south-facing balcony with the higher DLI and temperature compared to other balconies, lettuce growth was promoted. Along with such a fast growth, the seed stalk development of the lettuce occurred faster in the south-facing balcony. The increase of DLI was identified to promote the growth and quality of plants as well as florescence (Oh et al., 2009). The seed stalk of lettuce develops under the condition of high temperature and long day length (Silva et al., 1999). As the growth speed as well as the seed stalk development of the lettuce in the south-facing balcony was fast, the replacement time to the new plants for the continuous harvest of the lettuce was faster in the south-facing balcony than in other balconies.

Since the growing environment is different depending on the direction of the balcony windows and it changes depending on the season, it is necessary to understand the growing environment by direction of the windows and time (season) and choose the suitable crops. Plants need sunlight and the required amount of light varies by kinds of plants. Foliage plants, usually grown in the house, grow well indoors with a small amount of light (Torres and Lopez, 2010). Peace lily can grow with the very low DLI of less than $5 \mathrm{~mol} \cdot \mathrm{m}^{-2} \cdot$ day $^{-1}$, Dracena, Begonia and Kalanchoe tend to grow well with the DLI of $5-10 \mathrm{~mol} \cdot \mathrm{m}^{-2} \cdot \mathrm{day}^{-1}$. However, the vegetables in vegetable gardens need even more sunlight. For the better lettuce growth, the DLI of $10-20 \mathrm{~mol} \cdot \mathrm{m}^{-2} \cdot \mathrm{day}^{-1}$, which is more than the medium PPF, is required.

In spring (March-May), since the DLI is in the medium level of $10-20 \mathrm{~mol} \cdot \mathrm{m}^{-2} \cdot \mathrm{day}^{-1}$ in the east, west and south-facing balconies, it is appropriate for growing lettuce. However, in summer, it is difficult to grow lettuce as the PPF and temperature decreases. Since fruit vegetables such as chili and tomato grow well in the higher DLI of $20-30 \mathrm{~mol} \cdot \mathrm{m}^{-2}$. $\mathrm{day}^{-1}$, it is not easy to grow them in balconies unless a lot of light comes into the balconies. In the balconies with the low DLI of less than $10 \mathrm{~mol} \cdot \mathrm{m}^{-2} \cdot \mathrm{day}^{-1}$, it is recommended selecting the crops with a high shade endurance such as chive and ginger or grow sprout vegetables that can be harvested until the foliage leaves are out (Moon et al., 2007). If it is difficult to grow crops due to the low PPF, it is recommended applying supplementary light cultivation using artificial light.
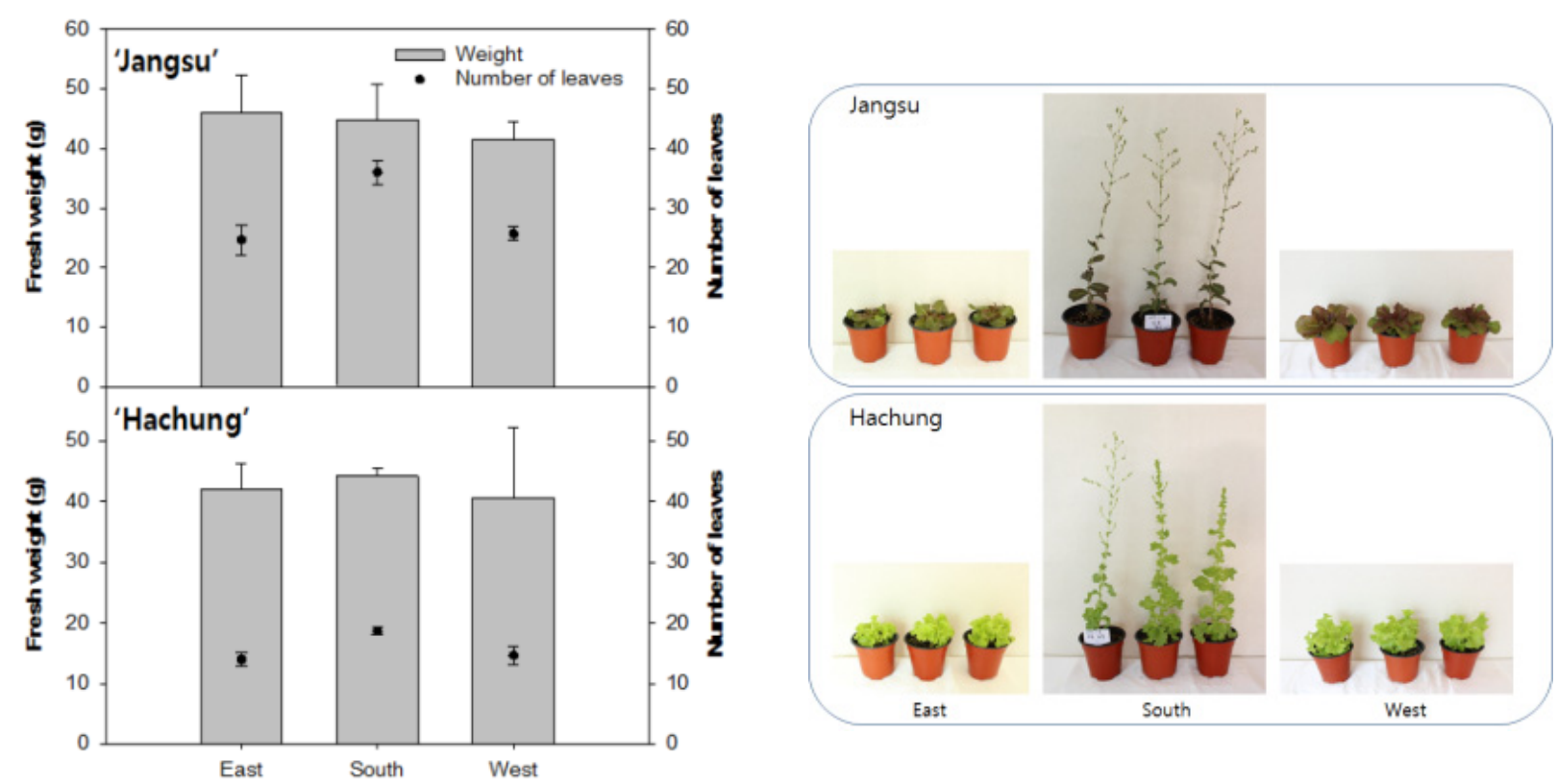

Figure 9. The growth of lettuce affected by the direction of apartment balcony (Jangsu: 83 days after transplanting, Hachung: 111 days after transplanting). 


\section{Conclusion}

Light is very important for plant growth. The incoming indoor PPF, time of incoming light and DLI changed depending on the direction of the balcony windows. According to the characteristics of incoming light, the temperature and relative humidity in the balconies were influenced. The incoming PPF was $20-50 \%$ of the outdoors in the south-facing balcony and $10-20 \%$ in the east and west-facing balconies. The environmental characteristics in the balconies were affected by season. In spring from March to May, balconies have a relatively better condition for plant growth as the DLI is around $10 \mathrm{~mol} \cdot \mathrm{m}^{-2} \cdot$ day $^{-1}$ and the average temperature is $25^{\circ} \mathrm{C}$, while it is hard to grow plants with the decreased incoming PPF and increased temperature and humidity as the solar altitude rises in summer from June to August. Balconies can maintain the average indoor temperature at around $10^{\circ} \mathrm{C}$ even in winter when the outdoor temperature is below zero. Therefore, it is necessary to select and manage the crops with the relatively lower light requirement like leaf vegetables by considering the characteristics of plant growth in balconies. It is also recommend growing plants from autumn to spring except for midsummer.

\section{References}

Burgess, P. 2009. Variation in light intensity at different latitudes and seasons, effects of cloud cover, and the amounts of direct and diffused light. In Forres, UK: Continuous Cover Forestry Group. Available online at http://www.ccfg.org.uk/ conferences/downloads/P_Burgess. pdf.

Dorais, M. 2003. The use of supplemental lighting for vegetable crop production: Light intensity, crop response, nutrition, crop management, cultural practices. In Canadial Greenhouse Conference (pp. 1-8).

Faust, J.E. 2002. First research report, Light management in greenhouses, I. Daily light Integral: A useful tool for the U.S. Floriculture industry. Retrieved from http://www.specmeters.com/assets/1/7/A051.pdf

Kim, H.C., J.Y. Sohn, and H.J. Park. 2006. Evaluation of the fire spread phenomena according to existence of balcony for apartment fires. J. Korean. Soc. Living Environ. Syst. 13(4):327-335.

Kim, M.S., Y.N. Jeong, and S.Y. Kim. 2015. Current status and implications on managing vegetable garden in apartment complexes. J. Archit. Inst. Korea plan. Des. 31(3):143-154. DOI: 10.5659/JAIK_PD.2015.31.3.143

Dzakovich, M.P., C. Gómez, and C.A. Mitchell. 2015. Tomatoes grown with light-emitting diodes or high-pressure sodium supplemental light have similar fruit-quality attributes. HortScience 50(10):1498-1502.

Ministry of Agriculture, Food and Rural Affairs (MAFRA). 2016. 2015 urban farming status report. Retrieved from MAFR A website: http://www.mafra.go.kr

Moon, J.H., S.G. Lee, Y.A. Jang, and W.M. Lee. 2007. Selection of vegetables and fertigation methods for veranda gardening. J. Bio-Environ. Control 16(4):314-321.

Morgan, L. 2013, November. Daily light integral (DLI) and greenhouse tomato production. The Tomato Magazine, Retrieved from https://www.specmeters.com/assets/1/7/2013_-_DLI_Greenhouse_Tomato1.pdf

Oh, D.M. and Y.A. Choi. 2006. Urban agriculture. Seoul, Korea: Hakjisa.

Oh, W., I.H. Cheon, and K.S. Kim. 2009. Photosynthetic daily light integral influences flowering time and crop characteristics of Cyclamen persicum. HortScience 44(2):341-344.

Rural Development Administration (RDA). 2016. Urban agriculture (The textbook for farming no. 178). Jeonju, Korea: Rural Development Administration. 
Silva, E.C., W.R. Maluf, N.R. Leal, and L.A.A. Gomes. 1999. Inheritance of bolting tendency in lettuce Lactuca sativa. L. Euphytica 109(1):1-7.

Son, M.S. 2009. Environment in apartment verandas at three floors, and change in growth of selected ornamental plants in simulated light intensities. MS thesis, Gyeongsang National University, Jinju, Korea.

Statistics Korea. 2017, August 02. The 2010 population and housing census. Retrieved from http://www.census.go.kr/ dat $/ y s r / y s r L i s t . d o ? q \_m e n u=5 \& q \_s u b=7$

The Seoul Institute. 2012. Urban agriculture activation plan for Seoul (Working Paper no. 2012-PR-35). Retrieved from https://www.si.re.kr/sites/default/files/2012-PR-35.pdf

Torres, A.P. and R.G. Lopez. 2010. Measuring daily light integral in a greenhouse. Department of Horticulture and Landsca pe Architecture, Purdue University. Retrieved from https://www.extension.purdue.edu/extmedia/HO/HO-238-W.pdf 